\title{
Proceeding
}

Supplementary Issue: Spring Conferences of Sports Science. III International Congress on Research and Didactics of Physical Education, 15-16 March 2018. Granada, Spain

\section{Augment reality and virtual reality for the improvement of spatial competences in Physical Education}

\author{
MELCHOR GÓMEZ-GARCÍA ${ }^{1}$, JUAN MANUEL TRUJILLO-TORRES ${ }^{2} \unlhd$, INMACULADA AZNAR-DÍAZ², \\ MARÍA PILAR CÁCERES-RECHE \\ ${ }^{1}$ Department of Didactics and School Organization, Autonomous University of Madrid, Spain \\ ${ }^{2}$ Department of Didactics and School Organization, University of Granada, Spain
}

\begin{abstract}
Young and mobile are an intense combination in entertainment. Mobile phones can also be a powerful tool in improving some teaching parameters, also in Physical Education. This research aims to test if Augmented Reality and Virtual Reality with mobile phones can have an impact on Physical Education students and their abilities in spatial orientation and distance estimation. In the investigation we have created two virtual and augmented scenarios, and a quantitative methodology has been used to analyze and contrast the learning tests carried out. The results show that these augmented worlds improve spatial orientation and estimation capacity. The study shows that it is convenient to develop activities and digital scenarios to incorporate mobile augmented reality in the learning of spatial orientation, at the same time as teaching skills are improved. Key words: AUGMENT REALITY, VIRTUAL REALITY, SPATIAL ORIENTATION, EDUCATION ESTIMATION.
\end{abstract}

\section{Cite this article as:}

Gómez-García, M., Trujillo-Torres, J.M., Aznar-Díaz, I., \& Cáceres-Reche, M.P. (2018). Augment reality and virtual reality for the improvement of spatial competences in Physical Education. Journal of Human Sport and Exercise, 13(2proc), S189-S198. doi:https://doi.org/10.14198/ihse.2018.13.Proc2.03

\footnotetext{
Corresponding author. Department of Didactics and School Organization, University of Granada, 18071 Granada, Spain. https://orcid.org/0000-0002-2761-3523

E-mail: jttorres@ugr.es

Supplementary Issue: Spring Conferences of Sports Science. III International Congress on Research and Didactics of Physical Education, 15-16 March 2018. Granada, Spain.

JOURNAL OF HUMAN SPORT \& EXERCISE ISSN 1988-5202

(c) Faculty of Education. University of Alicante

doi: 10.14198/jhse.2018.13.Proc2.03
} 


\section{INTRODUCTION}

The Augmented Reality and the Virtual Reality share the common feature of being synthetic versions for a user drawing from information anchored in 3D locations.

We can describe Augmented Reality (AR) as the increase of the Physical reality through the use of technologies which mix it with virtual objects. Thus it is a context which incorporates elements from the virtual world and elements from the physical world at the same time, being interactive in real time and allowing being showed in three dimensions. This ability to mix real and virtual objects in the same context allows using the Augmented Reality as an element of human interaction with various areas, such as computers, medicine or mathematics (Gómez, 2016). It is a new method to organize and interact with the information, and it can be an important cognitive support to do complex tasks.

Some examples of these complex tasks can be the activities which include some kind of risk, like the training of drivers of large vehicles, or learning to change a filter International Space Station (Regenbrecht, Baratoff \& Wilke, 2005). Another example is the company DHL, which equipped the workers of a warehouse with Augmented Reality glasses, and improved the efficiency in the order preparation nearly about a $25 \%$ (DHL, 2015).

But our focus in on the researches, that have already identified in the Augmented Reality the great potential to improve the learning (Billinghurst \& Duenser, 2012; Dede, 2009; Dunleavy, Dede \& Mitchell, 2009; Johnson, Adams \& Cummins, 2012; Squire \& Jan, 2007).

The mechanism in easy, thus it is about allowing exploring or looking at the physical world through a digital camera that adds and incorporates virtual objects on the own physical world. It does not replace the physical world with a virtual one, but it maintains the real world and complements it with virtual information overlaid to the real. In this way, the user never lose the contact with the physical world while they can interact with the overlaid virtual information (digital), thus obtaining an additional information that they cannot be detected by other means.

For that simply it is required a device which has a camera and a reading programme. The current smart phones include that camera, and the reading programme can be included with simple Apps.

If we add to this the emergence of Augmented Reality systems that allow to the users defining in a simple way their own AR scenes, like Aurasma (http://aurasma.com) or Layar (http://layar.com) we are in a situation in which teachers and students, we can design, build and administrate their own AR activities, as Barroso \& Gallego (2017) indicate.

Virtual Reality (VR) is the experience of being completely immerse in a purely virtual environment. The VR reproduces in 3D digital environments which it interact with dynamically, in a similar way to the presence in a real environment. The user feels they are inside the represented world, and they can interact with the represented environment like if it actually was a physical one. It is the computer which offers us the possibility of rebuilding the visual world, recreating and manipulating images.

In the immersive VR the user must bring a device for the eyes with a incorporated screen, and powered by a computer or mobile phone, this allows them receiving information and interaction concerning the objects and the setting which are watching through the screen. A specialised software and screen sensors let emulate 
the spatial movement, making it seems real, even accompanied by sounds and other effects. The not immersive VR is the same experience, but only with the computer.

Trindade, Fiolhais \& Almeida (2002) highlight three characteristics in order to understand the VT:

- Browsing, as efficient action and movement by the user within a Virtual Reality context.

- The interaction, as the relation in real time between the user and the 3D objects of the context.

- The immersion, as the feeling of presence in the figures environment by the technology of the Virtual Reality and as the ability to interact within this context.

RV systems, both immersive and the desktop ones, have their principal application in the entertainment field. But nowadays they become to be widely used by the professional training companies and by educational institutions as learning tools (Ritke-Jones, 2010).

\section{MATERIALS AND METHODS}

The present study has the aim of knowing the differences that can exist in the performance in the area of the physical education as a consequence of the method used: the text in print, the Augmented Reality and Virtual Reality. This will be worked in reference to spatial orientation and the estimation of measures.

In the investigation students of Physical Education carry out the same spatial orientation and estimation of distances activity in two types of different technological scenarios, with contents suited to the mobile technologies used, in order to find out if the students' performance is independent of the technology used, and if it is possible to see the differences which can exist in each of them.

A main support for the investigation is the design, then plan which gives a structure to the elements of study, so that the results will be credible, free from bias and generalizability. Because in our work different intervention proposals are studied -Augmented Reality, Virtual Reality, image and text in print- the methodological design more suitable is the quantitative, therefore it will help to highlight the primary aspects of each of them.

In addition, we will enrich this design with any qualitative element to understand the numerical data. It is easy to understand this combination, because the firsts give evidence and samples, and the seconds allowing us incorporating materials as observations, pictures or recordings, videos, and offering a complementary sense to the numerical data. So in this research prevails the quantitative approach, but it also has a qualitative element, searching for tendencies and typologies.

The research was carried out between students of Physical Activity and Sports Sciences, as part of their training in Information and Communication Technology, in the Autonomous University of Madrid.

The students belonged to 4 groups and they were assigned randomly to one of the three types of activities, according to the availability of material in that moment. This randomness minimizes the risk of bias in the observations. As they are class groups, we suppose that they are people with similar characteristics of age, degree of prior knowledges.

Of the 160 students that participated in the experience, 33 participated in the activity that used traditional learning methods with texts and images (called for our research Group A), 37 participated in the Augmented 
Reality activity (pinpointed in the Group B of the research), other 37 in the activity used Virtual Reality (Group C).

The activity of the students consisted in doing two scenes which have been represented in a similar way in print, in Augmented Reality (AR) and in Virtual Reality (VR). At first, students haven been invited to do a free exploration of the scenes, without constraints neither assessment.

At the end of activity it has asked to the students about the contents displayed through an online questionnaire with different sections, mainly referring to the subject of study -the spatial orientation and the distance estimation-. Also there were some question about the technologies used and their perception of the activity. The questionnaire was completed in the same IT classroom with the available computers, and with the mobile devices used in the activity, thus facilitating the completion of the questionnaire. Therefore, the research team was close to the students during the process in order to clarify possible doubts and facilitate the maximum number of questionnaires answered.

Questionnaires incorporated instructions to complete it, data classification like genre or age, 12 questions about the subject assessment (multiple choice and single answer), 1 open question about the perception of the activity and about the use of the devices, and another for free comments.

Data have been analysed after defining some variables, but in this piece of work the focus is on two of them:

Table 1. Selected variables

\begin{tabular}{lll}
\hline Variable & Type & Value \\
\hline Type of technology & Independent variable & Without digital technology \\
& & With Augmented Reality \\
& With Virtual Reality \\
Academic achievement & Dependent variable & Range 0-10
\end{tabular}

For the context designing it has taken into account the time limit to do the activity. As well it has taken into account the simplicity of the realization, so that any person could do the activities. It has been observes the technical ease for students could use the mobile devices and the Virtual Reality glasses. Moreover, it has been searched that contents were originals, in order to not being common in the education sector and thus preventing any prior knowledge that could influence in the evaluation of the activity.

Both scenes have been the St Peter's Square at the Vatican and the Apollo spacecraft in the Moon's surface. For both it has been done a material in printed and in digital format. The digital 3D elements of the moon scene were obtained from NASA webpage, and those of the St Peter's Square at the Vatican from the Warehouse webpage. Digital elements were processed and converted into a fbx format, with it 2 mobile applications were done for the Android operating system.

- The activity in printed and images was done on individuals tables where each participant read and reflect on the document before completing the questionnaire.

- The activity of Augmented Reality was carried out with 10 mobiles phones in which an app of Augmented Reality was previously installed, and that were accompanied by their respective AR codes to visualize the scenes. These codes were detected by mobiles and they could manipulate. The characteristic of increasing of the markers has been high enough for the aims of this research. 
- $\quad$ The Virtual Reality activity was done with 10 Virtual Reality glasses that were assembles with the mobiles, and those at the same time had the Virtual Reality app installed. In the design of the context care was taken, both in the environment exploration and in the relative speed in the virtual world, and in the user's vision in terms of pose and visual field.

Care has been taken when doing a good representation of the objects and environment, a simple access from the mobile device, a logic structure in the represented sequences, and a natural interaction with the different environments. It has been done an important work with the design of the interface of the user and how they were presented graphically the functionalities and the information.

Moreover, all the participants have had an initial instruction which has been guided by a teacher and accompanied with training videos, even with individual assistance until the user has been able to use the system independently.

One the participants understand their task and have material ready, they are asked to explore and browse for each scene. Each experience has been done in group of 10 participants, with a limit time approximately of 40 minutes. Then:

- GROUP A (without digital intervention, traditional method). They have been given 3 sheets with text, pictures and drawings to read in 15 minutes. Texts are explicit and with simple allusions to the further assessment questions. The same text is the audio that the participants of the other two groups listen to.

- $\quad$ GROUP B (intervention with Augmented Reality, mobile device). A mobile with headphones and two markers are given to explore freely during 15 minutes, accompanied by a descriptive audio of the scene which is the same that is read in the group A text.

- $\quad$ GROUP C (intervention with Virtual Reality, glasses with mobile device). A mobile with headphones connected with the VR glasses is given to do the walk around the scene in a immersive format during 15 minutes, accompanied by an descriptive audio which is the same as is read in the group A text.

After recording the activity and taking notes about the impressions and opinions of the students, materials were again prepared for the following group of ten people.

\section{RESULTS}

We have considered 3 groupings depending on the activity done:

- Group A: method with books and in print (traditional).

- Group B: with Augmented Reality (mobile phones with codes).

- Group C: with Virtual Reality (mobile phones with glasses).

160 questionnaires were completed: 53 from group A, 60 from Group B and 47 from Group C and students obtained punctuations with their answers.

The results in the groups are: 
Table 2. Summary

\begin{tabular}{llllll}
\hline Groups & $N$ & Minimum & Maximum & Average & Standard Deviation \\
\hline Group A & 53 & 1,3 & 9,3 & 4,56792453 & 1,81 \\
Group B & 60 & 0,7 & 8,4 & 5,46 & 1,62 \\
Group C & 47 & 1,9 & 6,2 & 4,11276596 & 1,12 \\
Total & 160 & 0,7 & 9,3 & 4,68110647 & 1,49 \\
\hline
\end{tabular}

In the first observation between Group $A(A=4,46 ; S D=1.81)$, Group $B(A=5.46 ; S D=1.62)$ and $G r o u p ~ C$ $(M=4.11 ; D T=1.12)$, it is outlined a difference in the obtained measures, with a higher value in the Group $B$. In order to check if these differences that can be observed in the average are statistically significant, we do a hypothesis contrasting, drawing from:

Ho: There are no significant differences in the assessment of the orientation and estimation activities done, depending on the technology used.

Ha: There are significant differences in the assessment of at least two groups in the orientation and estimation activities done, depending on the technology used.

If we compare in a box plot it can be observed hat in the Group $C$ the box in clearly more reduced than in the rest of groups, thus the dispersion in less. Furthermore, also the average and the median from Group $B$ have a higher value than in the Group A and this at the same time than the Group B.

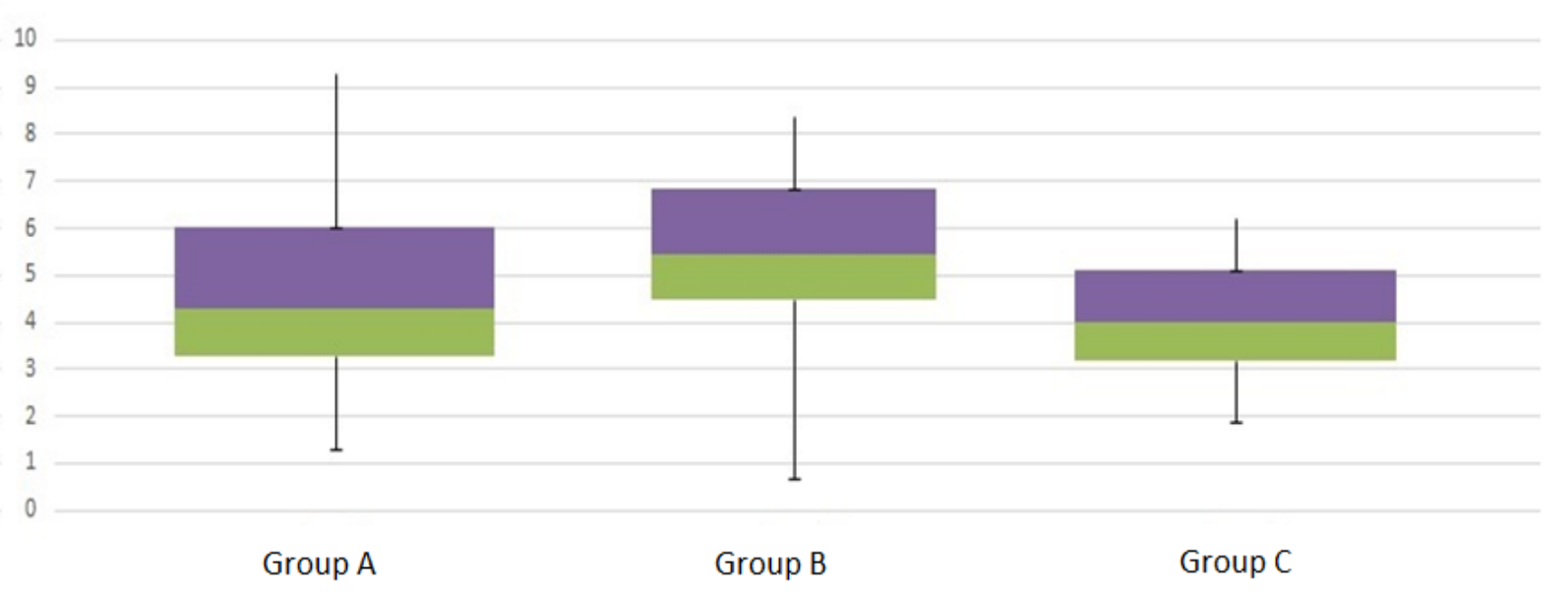

Figure 1. Box plot of the groups

In order to confirm these observed differences between the three groups we must choose the type of system to be used.as variables are independent and are not conditioned between them, we check that the distribution of the variables can be considered as normal. Thus, we contrast with NOVA that the difference is statistically significant for two groups. 
Table 3. Analysis of variance

\begin{tabular}{lllllll}
\hline Origin & Sum cuad & gl & Average C. & $F$ & Probability & V Critical for $F$ \\
\hline Between groups & 51,0319379 & 2 & 25,5159689 & 10,2217055 & 0,000067 & 3,053628264 \\
Inside groups & 391,911812 & 157 & 2,49625358 & & & \\
& & & & & & \\
Total & 442,94375 & 159 & & & & \\
\hline
\end{tabular}

As the probability is lower than 0.05 we must reject the null hypothesis and accept that there are significant differences between at least two of the groups. Now, in order to compare the groups in pairs they are applied the t-Student tests.

Test $t$ for samples A-B assuming unequal variances

\begin{tabular}{lll}
\hline & Variable 1 & Variable 2 \\
\hline Average & 4,56792453 & 5,46 \\
Variances & 3,37337446 & 2,66955932 \\
Observations & 53 & 60 \\
Hypothetical difference of the averages & 0 & \\
Degrees of freedom & 105 & \\
Statistical t & $-2,7127261$ \\
$\mathrm{P}(\mathrm{T}<=\mathrm{t})$ one-tailed & 0,00389992 \\
Critical value of $\mathrm{t}$ (one-tailed) & 1,65949538 \\
$\mathrm{P}(\mathrm{T}<=\mathrm{t})$ two-tailed & 0,00779985 \\
Critical value of $\mathrm{t}$ (two-tailed) & 1,98281522 \\
\hline
\end{tabular}

Test $t$ for samples $\mathrm{A}-\mathrm{C}$ assuming unequal variances

\begin{tabular}{lll}
\hline & Variable 1 & Variable 2 \\
\hline Average & 4,56792453 & 4,11276596 \\
Variance & 3,37337446 & 1,28244218 \\
Observations & 53 & 47 \\
Hypothetical difference of the averages & 0 & \\
Degrees of freedom & 88 & \\
Statistical t & 1,50937863 \\
$\mathrm{P}(\mathrm{T}<=t)$ one-tailed & 0,06739215 \\
Critical value of $t$ (one-tailed) & 1,66235403 \\
$\mathrm{P}(\mathrm{T}<=t)$ two-tailed & 0,1347843 \\
Critical value of $t$ (two-tailed) & 1,98728982 \\
\hline
\end{tabular}


Test $t$ for samples B-C assuming unequal variances

\begin{tabular}{lll}
\hline & Variable 1 & Variable 2 \\
\hline Average & 5,46 & 4,11276596 \\
Variances & 2,66955932 & 1,28244218 \\
Observations & 60 & 47 \\
Hypothetical difference of $\quad$ the & & \\
averages & & \\
Degrees of freedom & \multicolumn{2}{c}{104} \\
Statistical $t$ & 5,02858016 \\
$\mathrm{P}(\mathrm{T}<=\mathrm{t})$ one-tailed & $1,0355 \mathrm{E}-06$ \\
Critical value of $\mathrm{t}$ (one-tailed) & 1,65963744 \\
$\mathrm{P}(\mathrm{T}<=\mathrm{t})$ two-tailed & 0,000002 \\
Critical value of $\mathrm{t}$ (two-tailed) & 1,98303747 \\
\hline
\end{tabular}

\section{DISCUSSION}

Participants in the activity of Augmented Reality (group 2) obtained better results in the assessment of the spatial orientation and they were able to estimate better the distances than the rest of the groups, having an average $(A=5,46)$ almost one point higher than the other two. To a similar conclusion Quesada \& Sandoval (2015) come, with University students too, but from different knowledge areas of Mathematics and History. I do not want to say that all areas obtain benefit with the technology integration, thus these same authors also speak about mixed results in their respective knowledge areas, but there is an improvement of the students' performance in certain scientific subjects.

Moreover, students named the easy adaptation to the examination techniques done with Augmented Reality with mobile devices, something that facilitated their concentration when doing the activities. Cabero \& Barroso (2016) mention this adaptation, and though they refer more to the adaptation to the use of the technology, and rather than to the exploratory adaptation, which not always is there.

The use of devices of Virtual Reality with a mobile phone does not produce an significant improvement in relation to the activities done in traditional formats, and even in spatial orientation field can behave as an element of distraction and supposing a barrier for the learning, decreasing the performance against traditional methods. The average in group $C$ of Virtual Reality obtains even an average slightly lower $(A=4.11)$ than the group with traditional activity $(A=4.56)$, which without being statistically significant, but it is a point to keep in mind. Some students named as cause of a possible distraction in the technology that the use of the device drew more their attention than the activity itself (despite having had a little session of training).

These results are opposite to previous researches about Virtual Reality and learning (Bavelier \& Green,2016; Davidson \& Babelier, 2013), but Virtual Reality that was assessed in the researches mentioned was not immersive, but in desktop devices, something that probably change the learning effect. Furthermore, in these studies the Virtual Reality is used in gaming environments, which in an element of bias for the results, concerning pure exploring researches like our own one.

Some student even talked about problems in the quality of vision and little inconveniences or dizziness during some time. Probably, there is certain adaptation problem in order to visualize Visual Reality between the 
users that normally use glasses or lenses. This fact matches with some learning researches with mobile phones and different realities (Bonnin, 2017), that name the students' difficulty of adaptation to the immersive virtual environments.

\section{CONCLUSIONS}

The main conclusion is that Augmented Reality allows achieving improvements in some learning related to the spatial orientation and with the estimation of distances, against the use of traditional methodologies with paper format. Assessment averages of the group that did the activities with Augmented Reality were almost a point superior to the ones of the learning group with paper format.

This improvement is not reflected in the activities with immersive Virtual Reality. Furthermore, the averages obtained by the group of Virtual Reality are slightly lower, differences that are not statistically significant, but certainly they do not reflect any improvement regarding to the methods in physical reality.

This leads us to consider the importance that can have the learnings with increased digital contents to develop the spatial ability of the students in Physical Education, and to integrate the augmented methodologies as part of the designing of educational contents in this field. Similarly, it happens with the topic of the estimation of linear magnitudes (length, distance...).

Thus, we can consider that a part of the objectives have been fulfilled, because our interest in taking advantage of the mobile technologies in the learning of Physical Education is covered in the part the Augmented Reality, although is not in the Virtual Reality. This interest in using the mobiles phones has a double reason. In one hand, the great attractive that the digital technologies exert between the students of Physical Education and that is easily usable in order to caption their interest and improve their training. On the other hand, the possibilities of movement, register and work in open spaces that this little devices offer us, and so interesting result to those who provide training in Physical Education.

Probably, making this experience with mobiles more powerful phones than the ones used and in a higher number, had improved the experience and had saved some dizziness to the students that have done it. But further in the activity in next years, probably it will allow us to improve this aspect.

In the light of the outcomes of this research, it would be interesting to work in the field of the digital environments with mobiles phones in other areas of the Physical Education, and trying to integrate in a formal way in University programs.

\section{ACKNOWLEDGMENTS}

The present research his part of the competitive Project of Teaching Innovation called "Augmented Learning and Mobile (ALM). Application of the educative resources with augmented reality for mobile devices in the improvement of the training" (Ref. FPE_010.17_INN).

\section{REFERENCES}

Bavelier, D. y Green, C. (2016). Videojuegos que potencian el cerebro. Investigación y Ciencia, n²480. 
Barroso, J. y Gallego, O. (2017). Producción de recursos de aprendizaje apoyados en Realidad Aumentada por parte de los estudiantes de Magisterio. edmetic, 6(1), 2017, E-ISSN: 2254-0059; pp. 23-38 . Revista de Educación Mediática y TIC.

Billinghurst, M. y Duenser, A. (2012). Augmented Reality in the classroom. Computer, 45(7), 56-63. https://doi.org/10.1109/MC.2012.111

Bonnin, J.B. (2017). Mundos Virtuales y Reales. Estudio de la integración de la Realidad Aumentada y Virtual en educación formal. Tesis doctoral: Universidad Autónoma Madrid.

Cabero, J. y Barroso, J. (2016). Posibilidades educativas de la Realidad Aumentada. NAER, New Approaches in Educational Research, 5(1), 46-52.

Davidson, R. y Bavelier, D. (2013). Brain training: Games to do you good. Nature, [online] 494, pp.425426.

Dede, C. (2009). Immersive interfaces for engagement and learning. Science, 323(5910), 66-69. https://doi.org/10.1126/science.1167311

Dunleavy, M., Dede, C. y Mitchell, R. (2009). Affordances and limitations of immersive participatory Augmented Reality simulations for teaching and learning. Journal of Science Education and Technology, 18(1), 7-22. https://doi.org/10.1007/s10956-008-9119-1

Gómez, M. (2016). Móviles y mLearning. En J. Sánchez, J. Ruiz y M. Gómez (Eds.) Tecnologías de la comunicación y la información aplicadas a la educación (pp. 57-77). Madrid: Síntesis.

Johnson, L., Adams, S., \& Cummins, M. (2012). NMC Horizon Report: 2012 K-12 Edition. Austin, Texas: T. N. M. Consortium.

Quesada, M. y Sandoval, A. (2015). Realidad Aumentada como tecnología aplicada a la educación superior: Una experiencia en desarrollo. INNOVACIONES EDUCATIVAS. XVII. 41-49. https://doi.org/10.22458/ie.v17i23.1369

Regenbrecht, H., Baratoff, G., y Wilke, W. (2005). Augmented reality projects in the automotive and aerospace industries. Computer Graphics and Applications, IEEE, 25(6), 48-56. https://doi.org/10.1109/MCG.2005.124

Ritke-Jones, W. (2010). Virtual Environments for Corporate Education: Employee Learning and Solutions. IGI Global. https://www.igiglobal.com/book/virtual-environments-corporateeducation/37318 https://doi.org/10.4018/978-1-61520-619-3

Squire, K., y Jan, M. (2007). Mad City Mystery: Developing scientific argumentation skills with a placebased augmented reality game on handheld computers. Journal of Science Education and Technology, 16(1), 5-29. https://doi.org/10.1007/s10956-006-9037-z

Trindade, J., Fiolhais, C. y Almeida, L. (2002). Science Learning in Virtual Environments: A Descriptive Study. British Journal of Educational. https://doi.org/10.1111/1467-8535.00283

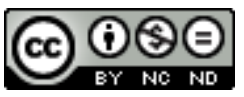

This title is licensed under a Creative Commons Attribution-NonCommercial-NoDerivs 4.0 Unported License. 